\title{
Audit of 26 years of obstetrics in general practice
}

\author{
G N Marsh, D M Channing
}

\begin{abstract}
To assess the feasibility and quality of general practitioner obstetrics an audit of 1223 consecutive obstetric deliveries over 26 years was carried out with standard clinical records. The perinatal mortality of 9.0 per 1000 births was significantly better than the national average of about 19.0 per 1000 for the overall period. During the audit home deliveries virtually stopped. The proportion of consultant bookings and deliveries more than doubled because of more stringent booking arrangements despite relocation of the previously isolated general practitioner unit to beneath the consultant unit. Abnormal deliveries also rose significantly. A "steady state" was achieved during the final 11 years in which $73 \%$ of women booked to be delivered by their general practitioner, $64 \%$ were admitted to the general practitioner unit, and $54 \%$ were delivered by their general practitioner. Though this is enough to sustain obstetric experience, the proportion might safely be increased.
\end{abstract}

\section{Introduction}

Obstetric care by general practitioners has long been controversial, with obstetricians criticising general practitioners for not producing adequate data. General practitioners, however, can and do have active roles in obstetric care and deliveries. To overcome the lack of available data and to support the role of general practitioners we carried out an audit of 26 years' obstetric care. We measured the quality of the outcome and the changes in the process of care and assessed whether an audit of this type was feasible and worth while.

Our practice had five partners during the period studied. The social class distribution of the 15000 patients approximates to the national average, and there are no sizable ethnic minorities. Each doctor has a personal list. Obstetric care used to be provided by a triad of doctor, nurse, and receptionist, but in the past decade a comprehensive primary health care obstetric team has developed. ${ }^{\prime}$ The team provides antenatal care and a postnatal examination of all mothers, irrespective of their delivery arrangements, though those booked for specialist care also attend hospital clinics, usually two or three times.

During 1962-8 home deliveries were fairly common,

Norton Medical Centre,

Norton, Stockton on Tees, Cleveland, TS20 1AN

G N Marsh, MD, general practitioner

D M Channing, DPHIL, research assistant

Correspondence to:

Dr Marsh.

Br Med J 1989;298: 1077-80 and other general practitioner cases were delivered in an isolated general practitioner maternity unit. Bookings were left to the general practitioner's discretion, but a specialist attended the unit once a week to see any problem patients. Difficulties during labour entailed transporting the patient by ambulance to a special unit $11 \mathrm{~km}$ away.

In mid-1968 the general practitioner maternity unit closed and resumed its function on one floor of a new hospital with other floors housing specialist units. General practitioners' bookings for the unit are

\section{Reasons for general practitioner being present during labour}

- Provides continuity and confidence

- Confirms normality with midwife

- Deals with minor problems

- Takes responsibility for referral to specialist

- Supports relatives (who are probably the general practitioner's patients)

- Encourages and assesses bonding

- Provides skilled hands in an emergency

- Enjoys it

assessed by a consultant, who refers any whom he or she thinks might be too high a risk to a monthly booking committee comprising two general practitioners, one consultant, and senior midwifery staff. A consensus view decides where the women are ultimately booked. The general practitioner unit also provides an early discharge unit to which suitable patients expressing this preference may be booked for discharge a few hours after delivery.

Each doctor, or a partner, is available 24 hours a day for his or her own bookings. The practice's policy has always been that, regardless of off duty hours and weekends, the partner who has given the antenatal care undertakes care in labour. Hence the normal off duty rota excludes obstetrics unless the doctor concerned is actually away. All partners believe that they should visit during the first stage of labour and be present at delivery, not only lest problems occur but also to continue the psychological and clinical support provided antenatally (box).

Throughout the paper the patients referred to were those of GNM.

\section{Method}

We analysed 1215 consecutive pregnancies of more than 28 weeks' gestation on GNM's list during 1962-88. The data were abstracted from standard clinical records into a register. Initially, interim totals and percentages were readily calculable; later a simple database on a home computer was set up for counting and statistical testing by two tailed $\chi^{2}$ tests. To examine time trends the audit was retrospectively divided into four periods: the six years up to the opening of the new maternity hospital (1962-8) (350 pregnancies); the next eight and a half years (1968-76) (363 pregnancies); the next five years (1977-81) (264 pregnancies); and the next six and a half years (1982-8) (238 pregnancies).

\section{Results}

Of the 1215 pregnancies, $481(39.6 \%)$ were first pregnancies (compared with $42 \cdot 2 \%$ in England and Wales in $\left.1980^{2}\right)$; 1223 babies were delivered, including 
eight sets of twins. Seven stillbirths and four neonatal deaths occurred, giving an overall perinatal mortality of 9.0/1000. The scatter and low number of these deaths precluded the detection of any underlying trend in perinatal mortality. The overall rate, however, was less than half the average perinatal mortality for England and Wales (19.0) and for the Northern region (estimated 20.0) during 1962-87 $(\mathrm{p}<0.01$ in both cases). ${ }^{34}$

Table I shows the results of the audit in the four periods and the significance of the differences found. Between the first and second periods (1962-8 and 196876), coinciding with the opening of the new district maternity hospital, the number of home bookings and deliveries fell significantly. A small proportion of women who would otherwise have been booked to deliver at home took advantage of the early discharge facility. Consultant bookings doubled from $10 \%$ to $20 \%$ and consultant deliveries from $20 \%$ to $40 \%$. The proportion of spontaneous vertex deliveries fell from $92 \%$ to $85 \%$, forceps deliveries increased from $4 \%$ to $9 \%$, and caesarean sections also increased. Smaller but still significant changes in the same direction occurred between the second period (1968-76) and the third and fourth periods combined (1977-88). The number of consultant bookings and deliveries increased again. The proportion of spontaneous vertex deliveries fell, whereas that of forceps deliveries and caesarean sections trebled compared with the first period. The proportions in the third and fourth periods, totalling
11 and a half years, were similar, suggesting the attainment of a steady state.

Table II shows the general practitioner unit's share of hospital bookings, admissions, and deliveries for the steady state period of the audit (1977-88). These are contrasted with figures from an Oxford hospital in 1987 and the combined NHS hospitals in England and Wales in $1980 .^{2}$

Table III compares the deliveries by type during 1977-88 with those nationally in $1980 .^{2}$ As the total distributions were so similar the considerably higher proportion of abnormal deliveries in the audit's consultant unit (compared with the national average for consultant units) was directly attributable to the much lower proportion of the total deliveries undertaken in that unit.

\section{Discussion}

LONG TERM AUDIT

Continuity of care is considered the hallmark of good general practice; I (GNM) now have the pleasure of delivering the babies of many women whom I delivered a generation ago. Thus the successful results of this long term audit have been personally gratifying. Several preconditions allowed the audit to be done.

Standard, carefully completed working records were used; there was therefore no extra research strain within the practice. The obstetric record card of the Royal College of General Practitioners was used

TABLE I-Bookings and deliveries and their outcome, 1962-88. Figures are numbers (percentages) unless stated otherwise

\begin{tabular}{|c|c|c|c|c|c|c|c|}
\hline & \multirow{2}{*}{\multicolumn{4}{|c|}{ Time period }} & \multirow[b]{3}{*}{ Total } & \multicolumn{2}{|c|}{ Significance of change ( $p$ value) } \\
\hline & & & & & & \multirow{2}{*}{$\begin{array}{l}1962-8 v \\
1968-76\end{array}$} & \multirow{2}{*}{$\begin{array}{c}1968-76 v \\
1977-88\end{array}$} \\
\hline & $1962-8$ & $1968-76$ & $1977-81$ & $1982-8$ & & & \\
\hline No of years in study & 6 & $8 \cdot 5$ & 5 & 6.5 & 26 & & \\
\hline No of pregnancies & 350 & 363 & 264 & 238 & 1215 & & \\
\hline No of babies & 354 & 363 & 264 & 242 & 1223 & & \\
\hline No of pregnancies/year & $58 \cdot 3$ & $42 \cdot 7$ & $52 \cdot 8$ & $36 \cdot 6$ & $46 \cdot 7$ & & \\
\hline \multicolumn{8}{|c|}{ Place where delivery booked to occur } \\
\hline Home & $126(36 \cdot 0)$ & $12(3 \cdot 3)$ & $1(0.4)$ & & $139(11 \cdot 4)$ & $<0.001$ & $<0.01$ \\
\hline Early discharge unit & NA & $35(9 \cdot 6)$ & $8(3.0)$ & $16(6 \cdot 7)$ & $59(4 \cdot 9)$ & $<0.001$ & $<0.01$ \\
\hline General practitioner unit & $187(53.4)$ & $240(66 \cdot 1)$ & $183(69 \cdot 3)$ & $157(66 \cdot 0)$ & $767(63 \cdot 1)$ & $<0.001$ & \\
\hline Consultant unit & $37(10 \cdot 6)$ & $76(20.9)$ & $72(27 \cdot 3)$ & $65(27 \cdot 3)$ & $250(20 \cdot 6)$ & $<0.001$ & $<0.05$ \\
\hline \multicolumn{8}{|c|}{ Transfer to consultant care } \\
\hline In pregnancy & $25(8 \cdot 0)$ & $39(13 \cdot 6)$ & $20(10 \cdot 4)$ & $21(12 \cdot 1)$ & $105(10 \cdot 9)$ & $<0.05$ & \\
\hline In labour ${ }^{\star}$ & $10(3 \cdot 2)$ & $29(10 \cdot 1)$ & $25(13.0)$ & $22(12 \cdot 7)$ & $86(8.9)$ & $<0.001$ & \\
\hline In puerperium ${ }^{\star}$ & $2(0.6)$ & & & & $2(0 \cdot 2)$ & & \\
\hline \multicolumn{8}{|c|}{ Place of delivery } \\
\hline Home & $116(33 \cdot 1)$ & $17(4 \cdot 7)$ & $2(0.8)$ & $1(0.4)$ & $136(11 \cdot 2)$ & $<0.001$ & $<0.001$ \\
\hline Early discharge unit & NA & $27(7 \cdot 4)$ & $7(2 \cdot 7)$ & $15(6 \cdot 3)$ & $49(4 \cdot 0)$ & $<0.001$ & \\
\hline General practitioner unit & $162(46 \cdot 3)$ & $175(48 \cdot 5)$ & $135(51 \cdot 1)$ & $114(47 \cdot 9)$ & $587(48 \cdot 3)$ & & \\
\hline Consultant unit & $72(20 \cdot 6)$ & $143(39 \cdot 4)$ & $120(45 \cdot 5)$ & $108(45 \cdot 4)$ & $443(36 \cdot 5)$ & $<0.001$ & \\
\hline \multicolumn{8}{|c|}{ Type of delivery } \\
\hline Spontaneous vertex & $322(92 \cdot 0)$ & $307(84 \cdot 6)$ & $201(76 \cdot 1)$ & $184(77 \cdot 3)$ & $1014(83 \cdot 5)$ & $<0.01$ & $<0.01$ \\
\hline Forceps & $13(3 \cdot 7)$ & $33(9 \cdot 1)$ & $38(14 \cdot 4)$ & $30(12 \cdot 6)$ & $114(9 \cdot 4)$ & $<0.001$ & $<0.001$ \\
\hline Breech & $6(1 \cdot 7)$ & $6(1 \cdot 7)$ & $5(1.9)$ & $4(1 \cdot 7)$ & $21(1.7)$ & & \\
\hline Caesarean section & $9(2 \cdot 6)$ & $17(4 \cdot 7)$ & $19(7 \cdot 2)$ & $18(7 \cdot 6)$ & $63(5 \cdot 2)$ & $<0.001 \dagger$ & \\
\hline Other & & & $1(0 \cdot 4)$ & $2(0 \cdot 8)$ & $3(0 \cdot 2)$ & & \\
\hline \multicolumn{8}{|c|}{ Outcome } \\
\hline Alive at 7 days & $350(98 \cdot 9)$ & $361(99 \cdot 4)$ & $260(98 \cdot 5)$ & $241(99 \cdot 6)$ & $1212(99 \cdot 1)$ & & \\
\hline Stillbirth & $3(0 \cdot 8)$ & $1(0 \cdot 3)$ & $2(0.8)$ & $1(0.4)$ & $7(0.6)$ & & \\
\hline Neonatal death & $1(0 \cdot 3)$ & $1(0 \cdot 3)$ & $2(0 \cdot 8)$ & & $4(0.3)$ & & \\
\hline
\end{tabular}

^Percentages are of non-consultant bookings. Four women booked to deliver in general practitioner unit were admitted to consultant ward in error; two women booked to deliver in consultant unit were delivered by general practitioner because of precipitate labour. $\nmid 1962-8 v 1982-8$.

TABLE II -Comparison of general practitioner unit's share of hospital bookings, admissions, and deliveries in present audit, Oxford, and England and Wales. Figures are numbers (percentages) of women

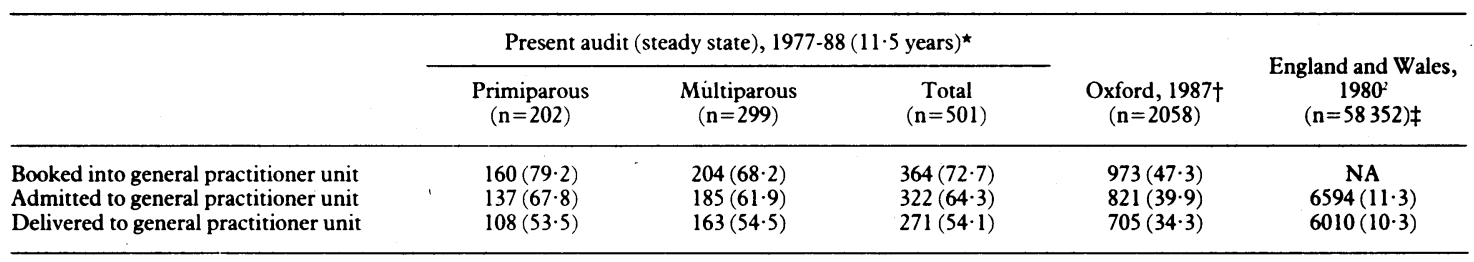

${ }^{\star}$ Figures include early discharge unit.

tM J V Bull. GP maternity unit: report for 1987. Oxford: John Radcliffe Hospital, 1988.

† Hospital In-Patient Enquiry (one in 10) sample; figures exclude 2058 cases in which ward of admission and delivery was not known. 
TABLE III-Comparison of deliveries by type in general practitioner and consultant units in present audit and England and Wales. Figures are numbers (percentages) of women

\begin{tabular}{|c|c|c|c|c|c|c|}
\hline & \multicolumn{3}{|c|}{ Present audit (steady state), $1977-88$ (11.5 years) } & \multicolumn{3}{|c|}{ England and Wales, $1980^{2 \star}$} \\
\hline & $\begin{array}{l}\text { General practitioner unit } \dagger \\
\qquad(\mathrm{n}=271)\end{array}$ & $\begin{array}{l}\text { Consultant unit } \\
(n=228)\end{array}$ & $\underset{(n=499)}{\text { Total }}$ & $\begin{array}{l}\text { General practitioner unit } \\
\qquad(n=6025)\end{array}$ & $\begin{array}{l}\text { Consultant unit } \\
(n=52327)\end{array}$ & $\begin{array}{c}\text { Total } \ddagger \\
(n=60410)\end{array}$ \\
\hline $\begin{array}{l}\text { Spontaneous vertex } \\
\text { Forceps } \\
\text { Ventouse extraction } \\
\text { Breech extraction } \\
\text { Caesarean section } \\
\text { Other }\end{array}$ & $\begin{array}{r}246(90 \cdot 8) \\
24(8.9) \\
1(0.4)\end{array}$ & $\begin{array}{r}136(59 \cdot 6) \\
44(19 \cdot 3) \\
2(0 \cdot 9) \\
9(3 \cdot 9) \\
37(16 \cdot 2)\end{array}$ & $\begin{array}{r}382(76 \cdot 6) \\
68(13 \cdot 6) \\
3(0 \cdot 6) \\
9(1 \cdot 8) \\
37(7 \cdot 4)\end{array}$ & $\begin{array}{r}5829(96 \cdot 7) \\
177(2 \cdot 9) \\
12(0 \cdot 2) \\
7(0 \cdot 1)\end{array}$ & $\begin{array}{r}39531(75.5) \\
6402(12.2) \\
372(0.7) \\
725(1.4) \\
5253(10.0) \\
44(0.1)\end{array}$ & $\begin{array}{r}46920(77 \cdot 7) \\
6841(11 \cdot 3) \\
395(0 \cdot 7) \\
748(1 \cdot 2) \\
5460(9 \cdot 0) \\
46(0 \cdot 1)\end{array}$ \\
\hline
\end{tabular}

«Hospital In-Patient Enquiry (one in 10) sample.

†Figures include early discharge unit.

†Total figures include 2058 deliveries in which ward of delivery was not known.

throughout and extracted from the patient's total record at the postnatal examination. If the mother did not attend for a postnatal examination the data were extracted when the family practitioner committee's claim form was submitted. I had an open list and took my fair share of newly registering families across the entire period. This minimised the problem of the aging list of the aging doctor and maintained a sufficient number of obstetric cases. Also, the audit was carried out on my personal list of patients, hence reducing recording by partners less committed to the data. Finally, help from a sophisticated primary health care team enabled me to sustain a list of 3000 to 3500 patients across the entire period. Small list sizes reduce clinical experience in this as in other aspects of clinical work. I have been attending 20-40 deliveries and doing two or three low forceps deliveries each year, which is quite enough to keep a trained, adequately refreshed general practitioner in practice. My $9 \%$ rate of transfer in labour-effectively three women a year-has given me adequate experience of the onset of difficulties.

\section{OUTCOME}

Perinatal mortality is the customary measure of outcome of obstetric care. At $9 \cdot 0$ per 1000 births this was significantly better than the national and regional rates across the whole period $(19 \cdot 0$ and 20.0 per 1000 respectively). If the rate had equated with that for England and Wales 12 more perinatal deaths would have been expected, and if it had equated with the Northern region's 13 or 14 more deaths would have been expected. This system of care, with about $60 \%$ of babies being delivered under the care of their general practitioner, thus gave excellent results.

CHANGES IN PROCESS OF CARE

Certainly the most important change during the 26

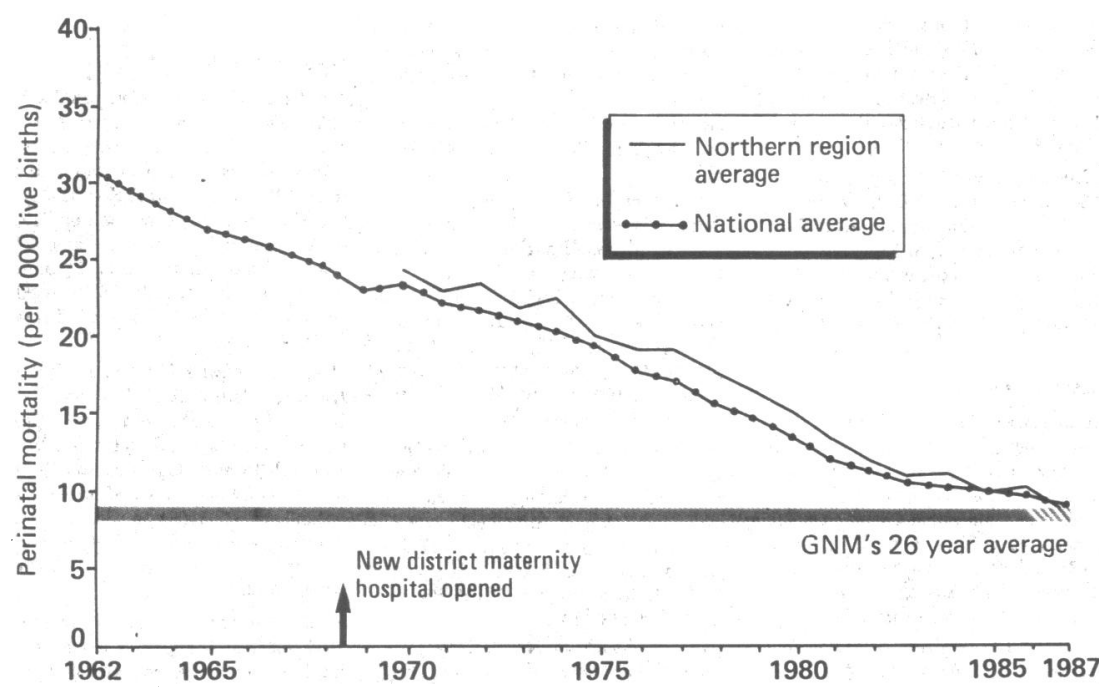

Perinatal mortality over 26 years of general practitioner obstetrics compared with national and Northern region rates years was the virtual disappearance of home deliveries. Although during 1962-76 I concurred with the prevailing view of obstetricians that home deliveries could be dangerous, since that time I have not dissuaded low risk mothers in their second or subsequent pregnancies from having a home delivery. In the event there has been only one such request, possibly because of our offer of care by their own doctor and midwife in a nearby, familiar hospital with the expressed aim of a normal physiological birth. In addition, mothers have been permitted to choose their duration of stay in hospital. During 1982-8 only $6 \cdot 3 \%$ chose early discharge, but discharge at 48 hours has become virtually the norm for normal mothers and babies. Largely because of this a puerperal ward has closed.

One of the paradoxes of this survey is that when the site of general practitioner deliveries was moved from an isolated unit $11 \mathrm{~km}$ from specialist facilities to the floor beneath them the proportion of consultant bookings actually increased from $11 \%$ to $21 \%$ and in the later periods to $27 \%$. Yet, despite this, transfers in pregnancy also increased from $8 \%$ to $14 \%$, ultimately settling at around $12 \%$. I believe that the rigorous criteria of booking and the high rates of transfer for fairly minor problems were due to obstetricians assuming a responsibility for all obstetric work within their district and being anxious about the newly available data on district perinatal mortality.

The significantly higher rate of transfer in labour, from $3 \%$ to about $12 \%$, once the units were in the same building arose largely from this ease of access as well as a greater belief in technology (such as intravenous drips, monitors) for even minor problems in virtually normal labours. In addition, general practitioners think that prolonged and often painful labours previously tolerated by women may be avoided by judicious use of oxytocic drugs and by using epidural analgesia when more normal methods are proving inadequate.

\section{CURRENT METHOD OF CARE}

The results show that after major changes in the first two periods studied there were virtually no differences between $1977-81$ and $1982-8$. In this practice $73 \%$ of women are booked for the general practitioner unit, $64 \%$ are admitted in labour, and $54 \%$ deliver there. The Oxford general practitioner unit, which is integrated with its consultant unit, has equivalent average figures of $47 \%, 40 \%$, and $34 \%$. The variation among practices in Oxford is, however, extreme, and in 1987 only two practices booked and delivered a higher proportion of women than I did. Whether our unit was alongside or integrated seems to have had little effect on the proportion of women delivered by their general practitioner compared with the effect of the individual general practitioner's enthusiasm. In recent years a steady state has been achieved, yet almost $60 \%$ of the women in our practice who delivered in the consultant unit had a spontaneous vertex delivery; perhaps the time has come to review booking criteria 
so that more of those women may be given the opportunity of obstetric care by their own general practitioner and midwife. ${ }^{5}$ The latest data on predicting risk should facilitate that process. ${ }^{\circ}$

The higher proportion of total deliveries that I undertake in the general practitioner unit lowers my rate of spontaneous vertex deliveries to $91 \%$ because I inevitably get more low forceps deliveries. Also those of my patients delivered in the consultant unit have a high proportion of abnormal deliveries $(40 \%)$, including forceps deliveries (19\%) and caesarean sections $(16 \%)$; these are considerably higher proportions than the average for consultant units in England and Wales. Thus increased participation of general practitioners in normal care would leave the work of a consultant unit more relevant and specialised. It should make such units more attractive to specialist obstetricians in training, athough conversely senior house officers doing the obstetric component of their training to be general practitioners will need to be made aware of the normal work going on in the associated general practitioner unit.

For the $60 \%$ of women who had spontaneous vertex deliveries in our consultant unit the close presence of a general practitioner unit was important. The philosophy of general practitioner obstetrics and the fastidious care of normal deliveries has spread to the specialist unit, largely by midwives who move from one to the other. Avoiding shaves and enemas, encouraging mobility in the first stage, emphasising the role of the companion in labour, softening the surroundings (with pictures, music, frequent baths), reducing the use of intravenous drips and monitors and other "technology" in normal deliveries, encouraging free choice of position in labour, avoiding episiotomies, and attending to measures of bonding are among the changes that have been absorbed across the years by the consultant unit and ultimately implemented in their normal deliveries.

\section{FUTURE AUDITING}

Now that national perinatal mortality has fallen to such a low rate and must eventually level off broader measures of care are needed. In the 1990s the process of care should be more rigorously scrutinised, aiming at lowering unnecessary interventions such as inductions, intravenous treatment, episiotomies, forceps and ventouse deliveries, and caesarean sections. In terms of outcome the aims should be a smaller proportion of low birthweight babies, improved Apgar scores, lower rates of transfer to special care baby units, and a higher proportion of breast fed babies. Assessing maternal satisfaction with labour must not be forgotten. Good practices and hospital units will have started such auditing already.

I thank my partners for their skill over the years when they have deputised for me; the consultants, registrars, and senior house officers for their care of the abnormal patients in my series; and Mrs K McFarlane for her careful assemblage of the records and secretarial skill.

1 Marsh GN. The primary health care team in obstetrics. In: Marsh GN, ed Modern obstetrics in general practice. Oxford: Oxford University Press, 1985:172-84

2 Department of Health and Social Security. Hospital in-patient enquiry matemity tables 1977-81, England and Wales. London: HMSO, 1986.

3 Office of Population Censuses and Surveys. Mortality statistics serial tables 1841-1980 (England and Wales). London: HMSO, 1985.

4 Office of Population Censuses and Surveys. Vital statistics 1987. London: HMSO, 1988.

5 Marsh GN. Encouraging GP intranatal care. Practitioner 1988;232:1127-31.

6 Reynolds JL, Yudkin PL, Bull MJV. General practice obstetrics: does risk prediction work? I R Coll Gen Pract 1988;38:307-10.

(Accepted 24 February 1989)
Disabled/handicapped people

After Attenborough: Arts and Disabled People. Carnegie Council Review. (Pp $\mathrm{x}+126$; figs; $\{5.95$ paperback, $\{6.70$ by post from distributor.) London: bedford Square Press, 1988. For
Best from distributor.) London: Bedford Square Press, 1988. For
Carnegie United Kingdom Trust. Carnegie United Kingdom Trust.
Distributed by Harper and Row DisDistributed by Harper and Row Dis-
tributors Limited, Estover Road, tributors Limited, Estover Road,
Plymouth, Devon PL6 7PZ. ISBN Plymouth, De

Concerned Technology 1989. CT89 Electronic Aids for People with Special Needs. J S Sandhu, S Richardson. $(\mathrm{Pp}$ 228; figs; $£ 15$ paperback, including UK postage and packing. Postage outside UK add £4.) 1988. Available from side UK add £4.) 1988. Available from Handicapped Persons Research Unit,
Newcastle upon Tyne Polytechnic, No I Coach Lane, Coach Lane Campus, 1 Coach Lane, Coach Lane Campus,
Newcastle upon Tyne NE7 7TW. Newcastle upon Tyne
ISBN 0-906721-41-5.

Environmental and public health IPCS International Programme on Chemical Safety: Environmental Health Criteria 80. "Pyrrolizidine Alkaloids." United Nations Environment Programme/International Labour Organisation/World Health Organisation. (Pp 345; figs; Sw frs 34 paperback.) Geneva: World Health Organisation, 1988. ISBN 92-4 154280-2.

\section{Gastroenterolog}

An Endoscopic Approach to Bilio Pancreatic Disease. L Familiari. ( $\mathrm{Pp}$ viii +196 ; figs and colour plates; $£ 33$.) Padua: Piccin, 1988. ISBN 88-2990404-X.

An Illustrated Guide to Gastrointestinal Motility. Ed D Kumar, S Gustavsson.
(Pp $x+470$; figs; \&65.) Chichester Wiley, 1988. ISBN 0-471-91949-7.

\section{General practice}

Oxford General Practice Series. 14 "Epidemiology in General Practice." Ed D Morrell. (Pp xi 155; figs \&15 paperback.) Oxford: Oxfor University Press, 1988. ISBN 0-19261603-X

\section{Genetic}

In Focus. "Molecular Basis of Inherited Disease." K E Davies, A P Read. Series editors D Rickwood, D Male. (Pp x +77; figs; £5.95 paperback.) Oxford: IRL Press, 1988 ISBN 1-85221-073-7.

Progress and Topics in Cytogenetics. Vo 7B. "Aneuploidy. Part B: Induction and Test Systems." Ed B K Vig, A Sandberg. Series editor $A A$ Sandberg. Sandberg. Series editor A A Sandberg. (Pp $x+342$; figs; \$160.) New York: Liss, 1988. Distributed by John
and Sons. ISBN 0-8451-2409-9.

\section{Geriatrics}

Age and Vulnerability: $a$ Guide to Better Care. O Stevenson. (Pp viii +136 6.95 paperback.) London: Arnold, 1989. ISBN 0-340-48670-8.

Ageing and Mental Handicap. J Hogg, S Moss, D Cooke. (Pp x+411 £27.50.) London: Croom

ISBN 0-7099-5718-1.

Counselling Older People: a Creative Response to Ageing. S Scrutton. (Pp iv +219; £8.95 paperback.) London: Arnold, 1989. ISBN 0-340-42073-1.

Promoting Health Among Elderly People. A Statement from a Working Group. A Kalache, T Warnes, D J
Hunter. (Pp 64; figs; $£ 2.50$ paperback.) London: King Edward's Hospital Fund for London, 1988. ISBN 1-870551-86-9.

\section{Haematology}

Current Studies in Hematology and Blood Transfusion. No 56. "Virus Inactivation in Plasma Products." J J Morgenthaler. Series editors A Morgen a rundsgard-Hansen. Hassig, A Lundsgaard-Hansen. ( $P$ p $\mathrm{x}+158$; figs; 164.60 .) Basel: Karger 1988. Distributed by John
Sons. ISBN 3-8055-4836-2.

Eosinophils: a Comprehensive Review, and Guide to the Scientific and Medical Literature. C J F Spry. (Pp xviii + 484 figs and colour plates; $£ 50$.) Oxford: Oxford University Press, 1988. ISBN 0-19-261408-8.

Hematology. Vol 9. "Coagulation and Bleeding Disorders: the Role of Factor VIII and von Willebrand Factor." Ed T S Zimmerman, Z M Ruggeri. Series editor K M Brinkhous. (Pp xvi +370; figs; \$150.) New York: Marcel Dekker, 1989. ISBN 0-8247-8013-2.

\section{Health care issues}

Anticipating and Assessing Health Care Technology. Vol 3. "Developments in the Regeneration, Repair and in the Regeneration, Repair and Reorganization of Nervous Tissue." Scenario Commission on Future
Health Care Technology. (Pp viii Health Care Technology. (Pp vilit 117; $£ 27.50$ paperback.) Dordrecht:
Kluwer, 1988. Distributed by MTP Kluwer, 1988. Distributed
Press. ISBN 0-89838-419-2.

Press. ISBN 0-89838-419-2.
Anticipating and Assessing Health Care Technology. Vol 4. "Health Care Application of Lasers: the Future Treatment of Coronary Disease." Scenario Commission on
Future Health Care Technology. ( $\mathrm{Pp}$ viii +67 ; figs; $£ 15.50$ paperback. Dordrecht: Kluwer, 1988. Distributed by MTP Press. ISBN 0-89838 410-9.

Anticipating and Assessing Health Care Technology. Vol 5. "Developments in Human Genetic Testing." Scenario Commission on Future Health Care Technology. (Pp x +15; figs; 24.95 (a) paperback.) Dordrecht: Kluwer ISBN 0-89838-411-7.

Anticipating and Assessing Health Care Technology. Vol 6. "Applications of the New Biotechnology: the Case of Vaccines." Scenario Commission o Future Health Care Technology. ( $\mathrm{Pp}$ viii+111; $\{24.95$ paperback.) Dordrecht: Kluwer, 1988. Distributed by MTP Press. ISBN 0-89838-
412-5.

Anticipating and Assessing Health Care Technology. Vol 7. "Computer Assisted Medical Imaging: the Case of Picture Archiving and Communica tions Systems (PACS)." Scenario Commission on Future Health Care Technology. ( $\mathrm{Pp} x+72 ; £ 15.50$ paperback.) Dordrecht: Kluwer,
1988. Distributed by MTP Press. ISBN 0-89838-413-3.

Anticipating and Assessing Health Care Technology. Vol 8. "Potentials for Home Care Technology." Scenario Commission on Future Health Care Technology. (Pp xi+146; £27.50 paperback.) Dordrecht: Kluwer, 1988. Distributed by MTP Press. ISBN 0-89838-420-6.

Cost and Choice in Health Care: the Ethical Dimension. Ed A Weale. (P $\mathrm{x}+85$; $£ 6.95$ paperback.) London: King Edward's Hospital Fund fo London, 1988. ISBN 1-870551-85-0.

Cost Versus Benefu in Cancer Care. Ed $B$ A Stoll. (Pp $x+118 ; £ 25$.) London: Macmillan, 1988. ISBN 0-33343594-X.

Medical Practice in a Multicultural Society. J H S Fuller, P D Toon. (Pp $\mathrm{x}+256$; £14.95 paperpack.) Oxford: Heinemann 0-433-00020-1.

Understanding the NHS: a Question of Incentives. P A West. (Pp 188; $£ 9.95$ paperback.) London: King Edward's Hospital Fund for London, 1988. Distributed by Oxford University Press. ISBN 0-19-724646-X.

\section{History of medicine}

The House of Industry Hospitals 1772 1987: The Richmond, Whitworth and Hardwicke (St Laurence's Hospital). A Closing Memoir. Compiled and edited by E O'Brien, L Browne, K O'Malley. (Pp xiii + 305; figs; cased edition 225 , de $x$ ins de colours, leather spine, \&120.) Dublin Anniversary Press, 1988. ISBN cased edition 1-870940-0.

Pauper to Patient: a History of the Roule Hospital Ballymoney 1840-1987. C Burns. (Pp xiv +152+index; figs; $£ 10$ plus $£ 1.50$ postage and packing.) 1988. Available from $\mathrm{Dr} C$ Burns, 10 Queen Street, Ballymoney, Co Antrim, N Ireland The Health Centre, Newal Road, Ballymoney County Antrim

Studies in Imperialism. "Imperial 